\title{
NUTRIÇÃO MINERAL DE HORTALIÇAS XXVIII. Tolerância de cultivares de tomateiro (Lycopersicon esculentum Mill) ao alumínio e ao manganês *
}

\author{
Homenagem à Escola Superior de Agricultura "Luiz de Queiroz" pelos \\ seus 75 anos de existência.
}

\author{
José Geraldo BaUmgartner ** \\ HenRique PaUlo HaAg *** \\ Gilberto Diniz DE Oliveira *** \\ Dilermando Perecin **
}

RESUMO

Dois experimentos foram conduzidos, em condições de casa-de-vegetação com o objetivo de caracterizar diferenças entre cultivares de tomateiro (Lycopersicum esculentum Mill) com relação à tolerância ao alumínio e ao manganês.

No primeiro experimento foram cultivados em Latossol Roxo (solo ácido, com níveis elevados de alumínio e manganês), seis cultivares de tomateiro: "Santa Cruz Kada", “Angela IAC 3946", "Vital", "Roma VF", "Pavebo 220" e "Ronita N", os três primeiros de crescimento indeterminado e os restantes de crescimento determinado.

No segundo experimento, os cultivares Santa Cruz Kada e Ronita $\mathrm{N}$ que apresentaram um contraste de desenvolvimento no solo ácido, foram cultivados em solução nutritiva de HOAGLAND \& ARNON, modificada para níveis de manganês $(0,5 ; 1,5$ e 3,0 ppm) e com adição de níveis de alumínio $(0,0 ; 10,0$ e 20,00 ppm).

Os resultados obtidos permitiram indicar o cultivar Santa Cruz Kada como mais tolerante ao alumínio que o cultivar Ronita $N$. A maior sensibilidade ao alumínio do cultivar Ronita $\mathrm{N}$ foi associada com uma maior exigência em cálcio e fósforo, com uma maior absorção de alumínio e também com efeito depressivo do alumínio na absorção dos nutrientes mencionados, em relação ao cultivar Santa Cruz Kada.

A tolerância do cultivar Santa Cruz Kada ao alumínio apesar de ser maior que a do Ronita $\mathrm{N}$ pode ser considerada de grau relativamente baixo, podendo-se esperar ainda, boas respostas dessas plantas à calagem nos cultivares em solos ácidos.

O comportamento dos cultivares frente aos níveis de manganês em solução nutritiva foi semelhante, não sendo observado qualquer efeito prejudicial do elemento nos níveis empregados.

* Parte da Tese de Doutoramento defendida na ESALQ, USP., pelo primeiro autor. Entregue para publicação em 16/12/76.

* Faculdade de Medicina Veterinária e Agronomia de Jaboticabal, UNESP, Jaboticabal, SP

** Escola Superior de Agricultura “Luiz de Queiroz”, USP., Departamento de Química, Piracicaba, SP 


\section{INTRODUÇÃO}

A cultura do tomateiro, além de ser pouco estudada no que concerne aos efeitos da acidez do solo sobre o seu desenvolvimento, tem apresentado respostas controvertidas ao emprego do calcário.

É prvável, com base nos estudos de FOY et alii (1973) que, pelo menos em parte, os resultados controvertidos da calagem na produção da cultura sejam devidos ao emprego de cultivares com diferentes graus de tolerância à acidez dos solos.

São escassos, no Brasil, os estudos para identificação de diferença varietal de tolerância à acidez, pelas diversas culturas, com exceção apenas da cultura do trigo, na qual se faz melhoramento genético para tolerância ao alumínio, desde 1925. (SILVA, 1976).

Sabe-se que a produção de pó calcário em nosso meio é ainda insuficiente para atender a demanda e este aspecto, associado a problemas de infraestrutura de transporte, limita o emprego do corretivo $\mathrm{cm}$ diversas regiões. A necessidade da aplicação de calcário em camada de maior profundidade do solo, em alguns casos, encarece sobremaneira o custo de produção, agravando o problema. Parece promissora a alternativa de emprego, no futuro, de espécies ou variedades vegetais tolerantes à acidez.

MERCADO \& VELASCO (1961) afirmam que o tomateiro (Lycopersicum esculentum Mill) é uma cultura muito sensível ao alumínio sendo mesmo sugerida como planta indicadora para a avaliação de disponibilidade de alumínio em solo ácido.

FOY et alii (1973), relatam que, até a data da publicação do trabalho que apresentaram sobre a tolerância do tomateiro ao alumínio (1973), não conheciam qualquer publicação a respeito da diferença varietal de tolerância do tomateiro àquele elemento.

LABANAUSKAS (1966), em trabalho de revisão de literatura, cita diversos autores que atribuem ao tomateiro uma especial sensibilidade ao excesso de manganês.

LAROCHE (1967), diz que escolheu o tomateiro como planta indicadora para experimentos sobre efeitos da relação $\mathrm{Ca}: \mathrm{Mg}: \mathrm{K}$ na nutrição de plantas porque, segundo a literatura, trata-se de planta que apresenta capacidade de troca de cations nas raízes de $34 \mathrm{~m} . \mathrm{e} . / 100 \mathrm{~g}$ de matéria seca. Pos essa razão absorve pouco cálcio e magnésio e portanto pode se adaptar à estados de acidez entre pH 5,5 e 7,0 e não deverá se beneficiar tanto da calagem como outras culturas tais como alfafa (Medicago sativa) e soja (Glycine max).

CAMARGO et alii (1965), cultivaram o tomateiro em solo ácido, 
com $\mathrm{pH}$ original de 4,8 e adicionaram doses crescentes, de 0 a $600 \mathrm{~g}$ de calcário $/ \mathrm{m}^{2}$. Não obtiveram resposta na produção da cultura e concluiram que o tomateiro é moderadamente tolerante à acidez.

Em contraposição, KAYAMA (1968), obteve efeitos positivos da calagem na produção da cultura verificando inclusive diminuição na incidência de podridão apical.

\section{MATERIAL E MÉTODOS}

A parte experimental constou de dois experimentos:

- Cultivo de seis cultivares de tomateiro em solo de condições especiais de acidez (níveis altos de alumínio e manganês) e de baixa fertilidade;

- Cultivo de dois cultivares de tomateiro, selecionados do primeiro experimento, em substrato de quartzo e irrigados com solução nutritiva contendo níveis variáveis de alumínio e/ou manganês.

\section{Primeiro Experimento}

Empregou-se um solo "Latossol roxo" situado no município de Ribeirão Preto, S.P., cujas características químicas são as seguintes:

Resultados Analíticos (*)

$\mathrm{pH}=5,4$

carbono $=2,6 \%$

fósforo solúvel $\left(\mathrm{H}_{2} \mathrm{SO}_{4} 0,05 \mathrm{~N}\right)=3 \mathrm{ug} / \mathrm{ml}$

potássio trocável $=39 \mathrm{ug} / \mathrm{ml}$

cálcio trocável $=2,1 \mathrm{e} \cdot \mathrm{mg} / 100 \mathrm{ml}$

magnésio trocável $=0,8 \mathrm{e} \cdot \mathrm{mg} / 100 \mathrm{ml}$

alumínio trocável $=1,80 \mathrm{e} \cdot \mathrm{mg} / 100 \mathrm{ml}$
Interpretação (**) acidez média

alto

baixo

médio

médio

médio

alto

O solo apresentou ainda um teor de manganês solúvel determinado segundo LINDSAY (1969), de $28,6 \mathrm{ppm}$ e um teor total do elemento de 730 ppm empregando-se a metodologia de JACKSON (1964).

Esse solo foi coletado da camada superficial do terreno $(0-30 \mathrm{~cm}$ de profundidade), seco ao ar e peneirado (peneira de malha de $6 \mathrm{~mm}$ ).

* Laboratório da Seção de Fertilidade do Solo do Instituto Agronômico de Campinas, S.P. Resultados expressos em termos de T.F.S.A.

* CATANi, R.A.; JACINTO, A.O. 1974. Análise química para avaliar a fertilidade do solo. Boletim técnico-científico "E.S.A. Luiz de Queiroz", Piracicaba, S.P. 57 pg. 
Em seguida foi colocado em três caixas de madeira com dimensões de $1 \times 1 \times 0,15 \mathrm{~m}$. O solo contido em uma das caixas recebeu o seguinte tratamento: $300 \mathrm{~g}$ de calcário dolomítico $(25,7 \%$ de $\mathrm{CaO}$ e $18 \%$ de $\mathrm{MgO}$ ), finamente moído, foram incorporados e incubados por cinco dias, com a umidade do solo mantida próxima à capacidade de campo. Em seguida adicionaram-se as seguintes quantidades de fertilizantes: $300 \mathrm{~g}$ de superfosfato simples $\left(20 \%\right.$ de $\left.\mathrm{P}_{2} \mathrm{O}_{5}\right), 20 \mathrm{~g}$ de sulfato de amônio $(20 \%$ de $\mathrm{N})$ e $10 \mathrm{~g}$ de cloreto de potássio $\left(60 \%\right.$ de $\left.\mathrm{K}_{2} \mathrm{O}\right)$.

A mistura de fertilizantes foi incorporada uniformemente ao volume total do solo e esta adubação foi denominada de "padrão". Nas outras caixas o solo não recebeu calcário e a adubação constituiu-se em $1 / 5$ da quantidade empregada no tratamento "padrão" e foi denominada de "mínima".

Sementes dos cultivares de tomateiro, Santa Cruz Kada, Angela IAC 3946, Vital, Roma VF, Pavebo 220 e Ronita $\mathrm{N}$ foram semeadas no solo das caixas, em covas rasas, espaçadas de $9 \mathrm{~cm}$ na linha e $14 \mathrm{~cm}$ entre as linhas, na razão de 12 sementes por "cova". Em intervalos de seis dias após a germinação procedeu-se ao desbaste deixando-se $5,3,2$ e 1 plântulas por cova.

Os cultivares empregados apresentam as seguintes características (CHURATA MASCA, 1974-1975 e FILGUEIRA, 1972):

Santa Cruz Kada - crescimento indeterminado, ciclo médio, frutos graúdos arredondados de polpa fina, maturação apresentando "ombro verde", resistente à rachadura.

Vital - crescimento indeterminado, ciclo médio, fruto médio arredondado, maturação uniforme.

Angela IAC 3946 - crescimento indeterminado, ciclo médio, frutos pequenos alongados de polpa firme, maturação uniforme, resistência à rachadura e ao vírus Y.

Roma VF - crescimento determinado, ciclo médio tardio, frutos de tamanho e forma tipo Roma (padrão), maturação uniforme, resistente à rachadura e às doenças de Fusarium e Verticillium.

Pavebo 220 - crescimento determinado, ciclo médio, forma e tamanho dos frutos, tipo Roma, alongados, maturação apresentando ombro com restante do fruto de coloração verde intensa.

Rnita $\mathbf{N}$ - crescimento determinado, ciclo médio, frutos de tamanho e forma tipo Roma, maturação uniforme, resistente à rachadura e aos nematóides.

A característica típica de cultivares de crescimento determinado é apresentar uma inflorescência na "guia" principal sendo, por isso, mais ramificadas e de menor porte que os tomateiros de crescimento 
indeterminado, possibilitando plantio sem estaqueamento e colheita mecânica.

As sementes certificadas dos cultivares de crescimento indeterminado utilizadas foram provenientes da Agroceres S. A. (Igarapé, M.G., Brasil), enquanto que as sementes do cultivar Ronita N, da Peto Seed (EUA) e as do cultivar Roma VF, da Argrow (EUA).

Neste experimento adotou-se um delineamento de blocos ao acaso. Cada caixa de madeira contendo o solo com as características descritas, foi dividida em dois blocos. Desta forma obtidos quatro blocos onde, sem calagem e com adubação mínima, cada cultivar foi representado por uma linha de cinto plantas. De maneira similar foram obtidos dois blocos, de referência, onde os tomateiros foram cultivados nas condições consideradas "padrão".

Aos 15, 22 e 29 dias após a germinação as plântulas foram mensuradas em altura, desde a superfície do solo até a gema apical. Trinta dias após a germinação, as plântulas foram coletadas desprezando-se o sistema radicular e foram postas a secar em estufa a $70^{\circ} \mathrm{C}$ durante vários dias.

\section{Segundo Experimento}

Os cultivares de tomateiro Santa Cruz Kada e Ronita N, selecionados no primeiro experimento, foram cultivados em solução nutritiva de acordo com o seguinte procedimento:

Empregou-se solução nutritiva 2 de HOAGLAND \& ARNON (1950) *, modificada quanto ao fornecimento de ferro. Este foi fornecido em concentração idêntica à fórmula original, na forma de Fe-EDTA.

Níveis de manganês foram obtidos por acréscimo nas doses $\mathrm{MnCl}_{2} \cdot 4 \mathrm{H}_{2} \mathrm{O}$, na referida solução. Desta forma foram estabelecidos os seguintes níveis do nutriente: 0,5 $\left(\mathrm{Mn}_{1}\right)$, 1,5 $\left(\mathrm{Mn}_{2}\right)$ e 3,0 $\mathrm{ppm}\left(\mathrm{Mn}_{3}\right)$.

Soluções de alumínio com concentrações de $10,0\left(\mathrm{Al}_{1}\right)$ e $20,0\left(\mathrm{Al}_{2}\right)$ ppm do elemento foram obtidas a partir de uma solução de $\mathrm{Al}_{2}\left(\mathrm{SO}_{4}\right)_{3} \cdot 18 \mathrm{H}_{2} \mathrm{O}$.

Usou-se como substrato, $1.500 \mathrm{~g}$ de quartzo moído (malha de $4 \mathrm{~mm}$ ) colocados em sacos plásticos que apresentavam perfurações na parte basal. Em cada saco plástico foram colocadas 10 sementes de cada um dos cultivares. Após a semeadura foram feitas várias irrigações diárias, com água destilada.

* HOAGLAND, D.R. \& ARNON, D.I. 1950. The water culture method for growing plants without soil. Circular 347. The College of Agriculture. University of California, Berkley. USA 
Três dias após a germinação substituiu-se na irrigação a água destilada, pela solução 2 de HOAGLAND \& ARNON. Sete dias após a germinação procedeu-se a um desbaste deixando-se duas plantas por saco.

Logo após o desbaste iniciou-se um esquema de irrigação em que as soluções nutritivas (3 níveis de manganês) foram fornecidas alternadamente com as soluções de alumínio (3 níveis). Ao nível zero de alumínio $\left(\mathrm{Al}_{0}\right)$ correspondeu o emprego de água destilada. Foram feitas irrigações 3 vezes ao dia, bem espaçadas (8,13 e 17 horas), obedecendo a um ciclo que completava-se a cada dois dias, da seguinte forma: solução nutritiva - solução de alumínio - solução nutritiva e (dia seguinte), solução de alumínio - solução nutritiva - solução de alumínio. O excesso percolado era descartado antes do início de nova irrigação. Empregaram-se $100 \mathrm{ml}$ das soluções em cada irrigação.

Decorridos 40 dias após a germinação as plantas foram mensuradas em altura e coletadas, separando-se inicialmente o sistema radicular da parte aérea. Em seguida, essas partes das plantas foram submetidas à lavagem segundo técnicas usuais (SARRUGE \& HAAG, 1974).

As partes aéreas das plantas foram subdivididas em folhas superiores, folhas inferiores e hastes e juntamente com as raízes foram postas a secar a $70^{\circ} \mathrm{C}$ durante vários dias.

O material assim obtido foi analisado para fósforo, cálcio, ferro, manganês e alumínio segundo métodos descritos em SARRUGE \& HAAG (1974). Com exceção do fósforo que foi determinado por colometria os demais elementos foram determinados pela técnica da espectrofotometria de absorção atômica.

Para o esquema estatístico empregou-se um delineamento inteiramente casualizado, tipo fatorial $3 \times 3 \times 2$ (níveis de alumínio, três níveis de manganês e dois cultivares de tomateiro), com 6 repetições.

\section{RESULTADOS E DISCUSSÃO}

\section{Primeiro Experimento}

\section{Aspectos Gerais}

Observou-se desde o início um melhor desenvolvimento dos cuilivares Santa Cruz Kada e Angela IAC 3946 nas condições de solo correspondentes à adubação "mínima", predominando ambos, sensivelmiente sobre os demais cultivares. Os mesmos cultivares, no solo que recebeu a adubação "padrão", juntamente com o cultivar Ronita N, predominaram sobre os demais, até 15 dias após a germinação, havendo tendência, posteriormente, para diminuição das diferenças. 
O aspecto apresentado por todos os cultivares desenvolvidos com adubação "mínima" refletia uma má nutrição generalizada. As plantas apresentavam pequeno crescimento mas uma coloração normal das folhas não sendo, por este aspecto, identificado qualquer sintoma de carência ou excesso.

\section{Altura das plantas}

Os dados de altura média das plantas nas diversas épocas e nas duas condições (adubação padrão e mínima) são apresentados na Tabela 1. A análise estatística foi feita para as diferenças médias dos dados obtidos pelo cultivo nas duas condições de solo.

Tabela 1 - Altura das plantas (cm), em diferentes épocas (dias após a germinação): média de 4 repetições para os tratamentos correspondentes ao cultivo em solo com adubação "mínima" e de 2 repetições para o cultivo em solo com adubação "padrão" e respectivas diferenças (A/M = adubação mínima; $\mathrm{A} / \mathrm{P}=$ adubação padrão; Dif. = diferença $)$.

Altura média das plantas em diferentes épocas e respectivas diferenças

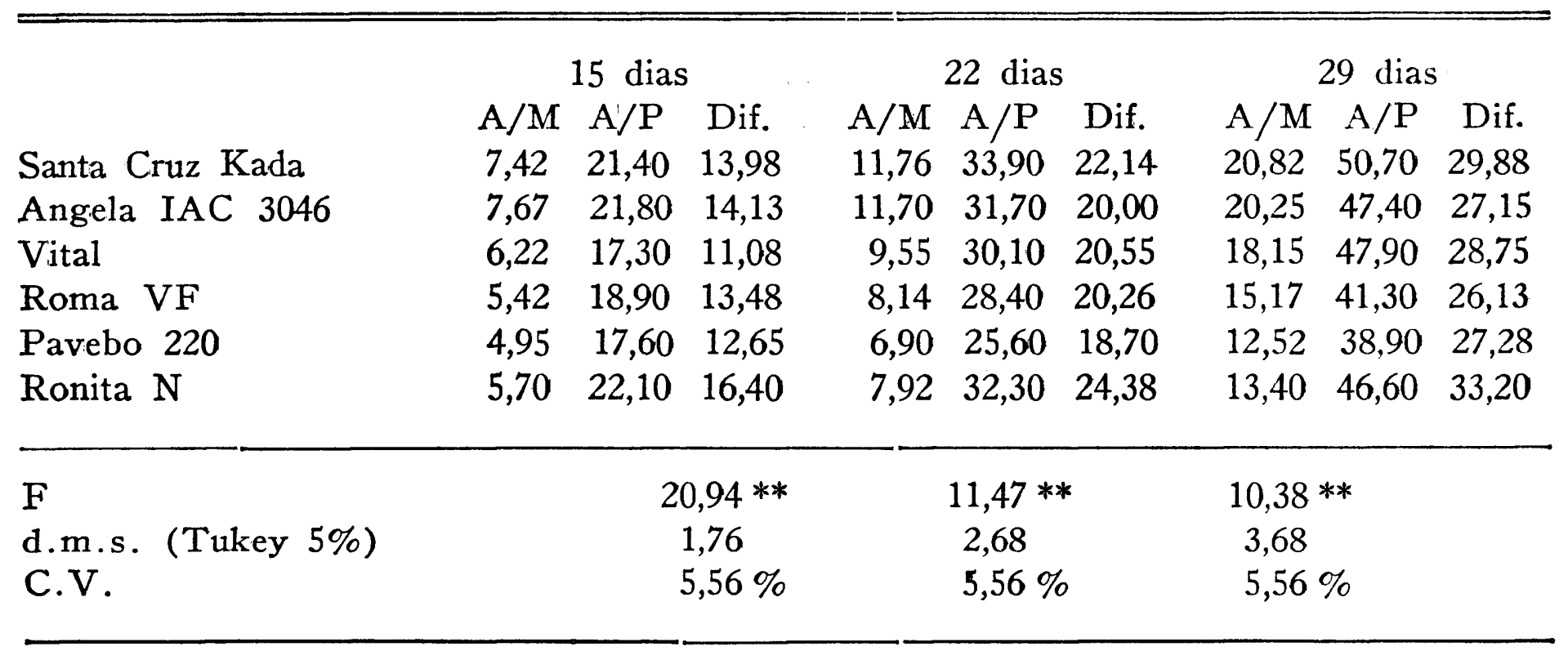

* Significativo a $1 \%$.

Os dados mostram que o cultivar Ronita $\mathrm{N}$, que não apresentou a menor altura entre todos, apresentou, todavia, a maior diferença de desenvolvimento entre as plantas cultivadas em solo com adubação "mínima" e em solo com adubação "padrão". 
Neste aspecto este cultivar destacou-se dos demais sendo a diferença altamente significativa. Considerando ainda o parâmetro diferença média de altura de plantas, nas duas condições de solo, verifica-se que o valor menor flutuou entre os restantes cultivares em função do estádio de desenvolvimento. Verificou-se portanto um maior efeito da acidez do solo sobre a altura das plantas do cultivar Ronita $\mathbf{N}$ não ficando bem definida uma diferença entre os demais cultivares.

Peso da matéria seca

Os resultados referentes ao peso médio de matéria seca das plantas cultivadas nas duas condições de solo e as respectivas diferenças säo apresentadas na Tabela 2.

Tabela 2 - Peso (g) de matéria seca (parte aérea) de plantas colhidas aos 30 dias após a germinação. Média de 4 repetições para os tratamentos correspondentes ao cultivo com adubação mínima e de 2 repetições para o cultivo com adubação padrão e respectivas diferenças. ( $\mathrm{A} / \mathrm{M}=$ adubação "mínima" e $\mathrm{A} / \mathrm{P}=$ adubação "padrão").

\begin{tabular}{|c|c|c|c|}
\hline \multirow[t]{2}{*}{ Cultivares } & \multicolumn{3}{|c|}{$\begin{array}{c}\text { Peso médio de matéria seca aos } 30 \text { dias e respectivas } \\
\text { diferenças }\end{array}$} \\
\hline & $\mathrm{A} / \mathrm{M}$ & $\mathrm{A} / \mathrm{P}$ & Diferença \\
\hline Santa Cruz Kada & 0,53 & 2,50 & 1,97 \\
\hline Angela IAC 3046 & 0,55 & 4,10 & 3,55 \\
\hline Vital & 0,48 & 3,10 & 2,62 \\
\hline Roma VF & 0,47 & 2,90 & 2,43 \\
\hline Pavebo 220 & 0,37 & 2,40 & 2,03 \\
\hline Ronita N & 0,31 & 3,50 & 3,10 \\
\hline $\mathrm{F}$ & & & $102,05 * *$ \\
\hline $\mathrm{C} . \mathrm{V}$ & & & $4,75 \%$ \\
\hline d.m.s. (Tukey 5\%) & & & 0,28 \\
\hline
\end{tabular}

** Significativo a $1 \%$.

Da mesma forma que para os dados de altura das plantas, também pra os de peso de matéria seca a análise estatística e as considerações foram feitas sobre as diferenças.

Os dados de peso de matéria seca voltam a confirmar o cultivar Ronita $\mathrm{N}$ como um dos mais sensíveis, apresentando juntamente com 
- cultivar Angela IAC 3946, as maiores diferenças de peso entre as plantas cultivadas em solo com adubação "mínima" e adubação "padrão".

Por outro lado, neste mesmo parâmetro, o cultivar Santa Cruz Kada mostrou-se nitidamente mais tolerante.

Um aspecto interessante a se destacar é que os cultivares Santa Cruz Kada e Angela IAC 3946 apresentaram a mesma produção de matéria seca quando cultivados no solo com a adubação "mínima" mas diferiram bastante em termos de resposta à adubação "padrão" do solo. A produção de matéria seca do cultivar Santa Cruz Kada foi muito inferior ao do Angela IAC 3946, com adubação "padrão" e este fato contribuiu em grande parte para que, entre os dois, o cultivar Santa Cruz Kada fosse considerado o mais tolerante às condições do solo que recebeu adubação "mínima".

Em vista desses resultados obtidos e comparando-os com os dados de altura de plantas verifica-se que os maiores contrastes de desenvolvimento das plantas nas condições de solo não corrigido foram apresentados pelos cultivares Santa Cruz Kada e Ronita $N$ entre os seis cultivares pesquisados. Esta relativa tolerância (Santa Cruz Kada) e susceptibilidade (Ronita N) não podem ser referidas exclusivamente à acidez do solo porque, nas duas condições de solo, a variável não foi apenas calagem mas também níveis de adubação. A adubação do solo, denominada "mínima", foi considerada indispensável à sobrevivência das plantas e, as doses dos adubos não puderam ser iguais às da adubação "padrão" porque, provavelmente o fósforo atenuaria em excesso ou até eliminaria os efeitos da acidez do solo. Todavia, é provável que a acidez do solo tenha tido representativa participação no mau desenvolvimento das plantas e que portanto, o contrase verificado de desenvolvimento entre os cultivares seria devido em proporção, à maior ou menor tolerância das plantas à acidez do solo. A extraordinária resposta de todos os cultivares à correção (calagem e nível mais alto de adubação) parece confirmar esta afirmação.

\section{Segundo Experimento}

\section{Aspectos Gerais}

As folhas inferiores foram escolhidas para representarem a parte aérea das plantas em vista do maior acúmulo dos nutrientes em estudo, com exceção do fósforo. Pelo confronto dos dados de concentração de nutrientes de folhas inferiores e raízes, pode-se fazer inferências a respeito da translocação dos elementos das raízes às partes aéreas. Todavia os resultados da análise de todas as partes das plantas são apresentados no apêndice, para alguma referênci ou consulta. Aparecem também no apêndice os valores de $\mathbf{F}$ da análise estatística de todos os quadros que, no texto, não apresentam esses valores. 
Foram analisados, nos tecidos das plantas, os nutrientes fósforo, cálcio e ferro, além dos elementos variáveis nos tratamentos, alumínio e manganês porque esses elementos são destacados na literatura pela relação com a tolerância de plantas ao alumínio e ao manganês, embora outros elementos também estejam envolvidos.

Aparecem ainda no texto, além dos dados de concentração dos elementos em raízes e folhas das plantas, as tabelas de dados de quantidade total absorvida de cada elemento. Esses dados foram consideradcs importantes na discussão porque os valores de concentração, como se sabe, são as vezes mascarados pelos efeitos de diluição ou concentração, promovidos pela atuação dos tratamentos no crescimento das plantas. Como cada valor, concentração ou quantidade absorvida, tem suas limitações, o confronto de ambos pode em alguns casos modificar uma interpretação que fosse feita por um dado isolado.

\section{Altura das plantas e peso da matéria seca}

Os dados de altura das plantas são apresentados na Tabela 3 e os pesos de matéria seca, na Tabela 4.

Considerando apenas a altura, já que cada cultivar apresenta características próprias de crescimento, foi estabelecido um tratamento padrão (0,5 ppm de $\mathrm{Mn}$ e $0,0 \mathrm{ppm}$ de $\mathrm{Al}$ ) como referência, pois c confronto direto de altura entre os doiscultivares por tratamento tem pouro interesse.

A alura das plantas foi a primeira característica a refletir os efeitos dos tratamentos pois foram percebidas diferenças logo na primeira semana após o início dos tratamentos.

As doses de alumínio apresentam efeito depressivo para a ailura de plantas do cultivar Ronita $\mathbf{N}$ sendo que as diferanças significativas foram obtidas apenas para a maior dose do elemento $(20 \mathrm{ppm})$ independentemente dos níveis de manganês. A altura das plantas do cultivar Santa Cruz Kada só foram afetadas pelas doses de alumínio, dentro do maior nível de manganês $(3,0 \mathrm{ppm})$, com efeito, curiosaniente benéfico.

Como se sabe, efeito benéfico do alumínio no crescimento de planlas para concentrações de até $13 \mathrm{ppm}$ de alumínio em solução, já foi verificado (Mc LEAN et al., 1928). Mas o efeito aqui obtido parese ser apenas aparente já que, as plantas de maior altura em decorrência do nível de alumínio, eram também mais delgadas e, como se verá, apresentaram menor peso de matéria seca que o tratamento padrão.

Este aspecto mostra um ponto negativo do parâmetro altura oie plantas nesse tipo de estudo, mas, apesar disso esse dado parece ser úil e tem sido usado com relativa freqüência por diversos autores. 
Tabela 3 - Dados de altura $(\mathrm{cm})$ média das plantas, obtidos aos 40 dias após a germinação. Média de 6 repetições.

\begin{tabular}{|c|c|c|c|}
\hline \multicolumn{2}{|c|}{ Níveis } & \multicolumn{2}{|c|}{ Altura média das plantas } \\
\hline $\mathrm{Mn}(\mathrm{ppm})$ & $\mathrm{Al}(\mathrm{ppm})$ & Ronita N & Santa Cruz Kada \\
\hline \multirow{3}{*}{0,5} & 0,0 & 61,25 & 73,08 \\
\hline & 10,0 & 60,00 & 73,41 \\
\hline & 20,0 & 50,25 & 75,25 \\
\hline \multirow{3}{*}{1,5} & 0,0 & 66,10 & 70,25 \\
\hline & 10,0 & 60,60 & 69,91 \\
\hline & 20,0 & 52,25 & 69,91 \\
\hline \multirow{3}{*}{3,0} & 0,0 & 64,30 & 69,25 \\
\hline & 10,0 & 60,25 & 81,25 \\
\hline & 20,0 & 55,25 & 75,58 \\
\hline \multirow{2}{*}{\multicolumn{2}{|c|}{$\begin{array}{l}\text { d.m.s. (Tukey 5\%) } \\
\text { C.V. }\end{array}$}} & $4,82 \%$ & $5,61 \%$ \\
\hline & & $5,85 \%$ & $5,48 \%$ \\
\hline
\end{tabular}

Tabela 4 - Peso (g) de matéria seca (parte aérea + raízes) de plantas colhidas aos 40 dias após a germinação. Média de 6 repetições.

\begin{tabular}{lccc}
\hline \multicolumn{2}{c}{ Níveis } & \multicolumn{2}{c}{ Peso médio de matéria seca } \\
\hline \hline Mn (ppm) & Al (ppm) & Ronita N & Santa Cruz Kada \\
\hline & 0,0 & 11,52 & 12,64 \\
& 10,00 & 9,97 & 12,12 \\
& 20,00 & 8,49 & 11,72 \\
\hline \multirow{3}{*}{1,5} & 0,0 & 13,43 & 10,73 \\
& 10,0 & 11,41 & 11,05 \\
& 20,00 & 9,31 & 11,41 \\
\hline 3,0 & 0,0 & 11,55 & 11,96 \\
& 10,0 & 9,46 & 9,95 \\
\hline d.m.s. (Tukey) & $5 \%$ (T) & 7,55 & 1,32 \\
C.V. & & 0,72 & $8,05 \%$ \\
\hline
\end{tabular}


A análise estatística mostra que os tratamentos com manganês tiveram efeito significativo sobre a altura das plantas e esse efeito traduziu-se em aumento de altura correspondente a aumento no nível de Mn fornecido. Mas, em apenas um caso, para o cultivar Ronita $\mathrm{N}$, o efeito do aumento na dose de $\mathrm{Mn}$ foi benéfico. Isto se verificou para o nível 0,0 (zero) de alumínio, quando a dose de Mn foi aumentada de 0,5 para 1,5 ppm em solução. Neste caso, o aumento de altura correspondeu também a um aumento no peso de matéria seca da planta confirmando ser mesmo um efeito benéfico.

Para o cultivar Santa Cruz Kada, tanto dentro do nível de $10 \mathrm{ppm}$ como no de 20 ppm de alumínio em solução, quando se aumentou o teor de $\mathrm{Mn}$ de 1,5 para 3,0 ppm na solução nutritiva, a este aumento correspondeu também um acréscimo significativo na altura das plantas. Novamente comparando esses valores com os de peso de matéria sera constata-se que não houve correspondência, isto é, o aumento da altura da planta não se correlacionou com o aumento de peso. Pelo contrário, dentro do maior nível de alumínio $(20 \mathrm{ppm})$ quando se aumentou o nível de $\mathrm{Mn}$, de 1,5 para 3,0 ppm na solução, ocorreu diminuição no peso das plantas.

Não parece portanto muito improvável que o aumento na altura das plantas em alguns tratamentos raduz um efeito deletério do tratamento.

Considerados isolados, os dados de peso otal de matéria seca parecem ser mais consistentes que os de altura de plantas na comparação dos resultados.

Através dos dados de peso de matéria seca pode-se observar um efeito mais acentuado das doses crescentes de alumínio sobre o desenvolvimento das plantas do cultivar Ronita $N$ do que sobre as plantas do cultivar Santa Criz Kada. O aumento da dose de alumínio foi depressivo ao desenvolvimento das plantas ern todos os níveis de Mn para o cultivar Ronita $\mathrm{N}$ e apenas nos níveis maiores de $\mathrm{Mn}$ e Al para o cultivar Santa Cruz Kada.

Avaliados através do peso de matéria seca das plantas, os efeitos de aumento de doses de manganês, foram os de inicialmente aumentar o desenvolvimento das plantas e depois voltar ao original para o cultivar Ronita N. Para as plantas de Santa Cruz Kada os efeitos foram variáveis em função dos níveis de alumínio, isto é, houve uma interação sìnificativa entre alumínio e manganês, dificultando a interpretação do efeito do Mn.

Generalizando e, para isso, reunindo os dados de peso de matéria seca e altura das plantas pode-se afirmar que o alumínio nas doses empregadas foi depressivo ao desenvolvimento das plantas de ambos os cultivares com efeito mais acentuado sobre o cultivar Ronita $\mathbf{N}$. O efeito do Mn foi ligeiramente benéfico ao cultivar Ronita $\mathrm{N}$ e complexo, 
em função da interação com níveis de alumínio, para o cultivar Santa Cruz Kada.

O efeito de Mn parece contraditório às informações da literalura que situam o tomateiro como cultura muito sensível ao elemento e que mencionam níveis tais como 2,0 ppm em solução excessivo para a cultura (CANDELA \& HEWITT, 1957).

Comparando os dados de peso e altura das plantas entre os dois experimentos verifica-se que houve uma relativa concordância pois o cultivar Ronita $\mathrm{N}$ que foi mais sensível ao solo ácido foi também mais afetado pelos níveis de alumínio em solução nutritiva. Por outro lado o cultivar Santa Cruz Kada que em solo corrigido apresentou peso de matéria seca bastante inferior ao cultivar Ronita $\mathrm{N}$ já, nas conāições normais de solução nutritiva ( $(0,5 \mathrm{ppm}$ de $\mathrm{Mn}$ e $0,0 \mathrm{ppm}$ de alumínio) apresentou produção de matéria seca superior. Isto indica que o comportamento dos cultivares não foi totalmente similar nas duas condiçöes.

Pode estar relacionado a este problema o fato de que o cultivar Santa Cruz Kada, nas condições "padrão" apresentou uma relação peso da parte aérea/peso de raiz de 9,02 enquanto que esta relaçao foi de 4,22 para o cultivar Ronita N. Por outro lado o efeito do aluminio deprimindo o desenvolvimento radicular foi mais acentuado para o cultivar Ronita N.

\section{Fósforo}

Os dados de concentração de fósforo nas folhas e raízes das plantas são apresentados na Tabela 5, os dados de quantidade total absorvida na Tabela 6 e os dados de concentração do elemento nas diversas parıtts da planta, na Tabela 7.

A análise estatística permite as seguintes observações sobre os dados da Tabela 5 .

\section{Efeito das doses de aluminio}

Cultivar Ronita $\mathrm{N}$ - Os aumentos das doses de alumínio fornecidas, deprimiram o teor de fósforo nas folhas e raízes das plantas mas o efeito foi dependente dos níveis de manganês na solução nutritiva (o efeito não foi verificado dentro do maior nível de manganês para as folhas).

Cultivar Santa Cruz Kada - Os aumentos nos níveis de alumínio não afetaram o teor de fósforo nas folhas mas deprimiram o teor do nutriente nas raízes, apenas dentro do nível de $0,5 \mathrm{ppm}$ de manganês na solução. 
Tabela 5 - Teor $(\%)$ de fósforo nas folhas inferiores e nas raízes. Média de 4 repetições.

\begin{tabular}{|c|c|c|c|c|c|}
\hline \multicolumn{2}{|c|}{ Níveis } & \multicolumn{2}{|c|}{$\mathrm{P}$ nas folhas inferiores } & \multicolumn{2}{|c|}{$\mathrm{P}$ nas raízes } \\
\hline $\mathrm{Mn}(\mathrm{ppm})$ & $\mathrm{Al}$ (ppm) & Ronita $\mathrm{N}$ & Sta. Cruz Kada & Ronita $\mathrm{N}$ & Sta. Cruz Kada \\
\hline \multirow{3}{*}{0,5} & 0,0 & 0,42 & 0,35 & 0,36 & 0,44 \\
\hline & 10,0 & 0,44 & 0,34 & 0,35 & 0,42 \\
\hline & 20,0 & 0,32 & 0,29 & 0,33 & 0,34 \\
\hline \multirow{3}{*}{1,5} & 0,0 & 0,41 & 0,34 & 0,34 & 0,35 \\
\hline & 10,0 & 0,38 & 0,35 & 0,32 & 0,39 \\
\hline & 20,0 & 0,33 & 0,31 & 0,34 & 0,37 \\
\hline \multirow{3}{*}{3,0} & 0,0 & 0,39 & 0,29 & 0,42 & 0,33 \\
\hline & 10,0 & 0,45 & 0,35 & 0,43 & 0,35 \\
\hline & 20,0 & 0,35 & 0,30 & 0,33 & 0,37 \\
\hline \multicolumn{2}{|c|}{ d.m.s. (Tukey 5\%) } & 0,04 & 0,06 & 0,04 & 0,04 \\
\hline \multicolumn{2}{|c|}{ C.V. } & $5,76 \%$ & $9,57 \%$ & $7,55 \%$ & $6,66 \%$ \\
\hline
\end{tabular}

Tabela 6 - Quantidade total (mg) absorvida, de fósforo, por duas plantas. Média de 4 repetições.

\begin{tabular}{|c|c|c|c|}
\hline \multicolumn{2}{|c|}{ Níveis } & \multicolumn{2}{|c|}{ Quantidade de $\mathrm{P}$ absorvida } \\
\hline $\operatorname{Mn}(\mathrm{ppm})$ & $\mathrm{Al}(\mathrm{ppm})$ & Ronita $\mathrm{N}$ & Santa Cruz Kada \\
\hline \multirow{3}{*}{0,5} & 0,0 & 52 & 49 \\
\hline & 10,0 & 44 & 46 \\
\hline & 20,0 & 33 & 37 \\
\hline \multirow{3}{*}{1,5} & 0,0 & 59 & 39 \\
\hline & 10,0 & 48 & 45 \\
\hline & 20,0 & 38 & 43 \\
\hline \multirow{3}{*}{3,0} & 0,0 & 51 & 41 \\
\hline & 10,0 & 46 & 43 \\
\hline & 20,0 & 31 & 34 \\
\hline \multicolumn{2}{|c|}{ d.m.s. (Tukey 5\%) } & 3 & 5 \\
\hline \multicolumn{2}{|c|}{ C.V. } & $5,00 \%$ & $6,73 \%$ \\
\hline
\end{tabular}


Tabela 7 - Concentração $(\%)$ de $\mathrm{P}$ nas diferentes partes das plantas, cultivadas nas condições "padrão" de solução nutritiva $\left.\mathrm{Mn}_{1} \mathrm{Al}_{0}\right)$. Média de 4 repetições.

\begin{tabular}{|c|c|c|c|c|}
\hline \multirow{2}{*}{ Cultivar } & \multicolumn{4}{|c|}{ Concentração de $\mathrm{P}$ na matéria seca } \\
\hline & $\begin{array}{c}\text { folhas } \\
\text { superiores }\end{array}$ & $\begin{array}{l}\text { folhas } \\
\text { inferiores }\end{array}$ & hastes & raízes \\
\hline Ronita N & 0,51 & 0,42 & 0,47 & 0,36 \\
\hline Santa Cruz Kada & 0,44 & 0,35 & 0,39 & 0,44 \\
\hline \multicolumn{5}{|c|}{$\begin{array}{l}\mathrm{F}(\text { entre cultivares })=25,00 * * \\
\mathrm{C} . \mathrm{V} .=4,74 \% \\
* *=\text { significativo a } 1 \%\end{array}$} \\
\hline
\end{tabular}

Efeito das doses de manganês

Cultivar Ronita N - Para os tratamentos que receberam $10,0 \mathrm{ppm}$ de alumínio o primeiro incremento de manganês $(0,5$ para $1,5 \mathrm{ppm})$ provocou decréscimo no teor de fósforo nas folhas e o segundo incremento (1,5 para $3,0 \mathrm{ppm}$ ), um aumento na concentração do nutriente no mesmo órgão. Nas raízes, o incremento de 1,5 para $3,0 \mathrm{ppm}$ de manganês na solução provocou também aumento na concentração de fósforo.

Cultivar Santa Cruz Kada - Os aumentos nos níveis de manganês não alteraram a concentração de fósforo nas folhas. Nas raízes verificou-se um efeito depressivo dos níveis de manganês na concentração de fósforo tanto dentro do nível 0,0 quanto no nível de $10,0 \mathrm{ppm}$ de alumínio.

Considerando os dados de quantidade total de fósforo absorvida pelas plantas (Tabela 6), verifica-se que, no geral, o efeito de níveis de alumínio foi bem característico na depressão da absorção do nutriente pelas plantas de ambos os cultivares. Os dados de quantidade total absorvida de fósforo inclusive acentuam diferenças observadas ccm relação à concentração do nutriente nas partes das plantas. O efeito dos níveis de manganês sobre a absorção de fósforo, embora sua avaliação fosse afetada pelo efeito dos níveis de alumínio no crescimento das plantas (interação alumínio x manganês), pode ser considerado, no total, como um efeito depressivo.

Os efeitos dos tratamentos sobre a absorção de fósforo pelas plantas foi mais acentuado no cultivar Ronita $N$ que no cultivar Santa Cruz Kada. Todavia, mesmo os menores teores de fósforo encontrados nas folhas das plantas $(0,29 \%$ para o cultivar Santa Cruz Kada e 0,32\% para o cultivar Ronita N) são valores considerados médios para a cultura 
(BIGHANM, 1966). Parece claro que as doses de alumínio e manganês apesar de deprimirem a absorção de fósforo pelos dois cultivares este efeito, isoladamente, não pode ser responsabilizado pelo menor desenvolvimento das plantas.

Confrontando-se os dados de concentração de fósforo nas folhas com a concentração nas raízes, pode-se inferir que o alumínio afetou mais a absorção do fósforo pelas plantas do que a translocação do nutriente das raízes às partes aéreas. A literatura aponta que, quando o alumínio é fornecido às plantas separadamente do fósforo, mesmo com emprego de diferentes técnicas, o alumínio não tem afetado a absorção do nutriente (CRUZ et alii, 1967; REES \& SIDRAK, 1961), mas que poderá afetar a translocacão do mesmo, das raízes às partes aéreas (CLARKSON, 1967). Neste caso, o alumínio assimilado liga-se fortemente às cargas negativas das paredes celulares possivelmente a grupos carboxílicos livres ou à cadeias de ácidos poligalacturônicos da lamela média da parede celular. Posteriormente as cargas superficiais de óxido de alumínio amorfo absorve e precipita o fósforo absorvido imobilizando-o na região das paredes celulares, nas raízes.

No presente experimento as doses de alumínio deprimiram o teor de fósforo tanto na parte aérea quanto nas raízes das plantas. Isto ocorreu apesar de se ter fornecido as soluções alternadamente, procurando-se minimizar os efeitos do alumínio sobre o fósforo, no meio e no fenômeno de absorção. Desta forma, como o efeito no translocação, pode-se inferir que o cultivar Santa Cruz Kada foi mais efetivo na utilização do fósforo do meio, na presença de alumínio, que o cultivar Ronita $\mathrm{N}$, e este é um fator comumente apontado como indicativo de maior tolerância ao alumínio (BROWN et alii, 1972).

Considerando que as quantidades de fósforo absorvidas no tratamento padrão $\left(\mathrm{Mn}_{1} \mathrm{Al}_{0}\right)$ representam as exigências dos cultivares, observa-se que, quando se aumentou a dose de alumínio, de 0,0 para $20,0 \mathrm{ppm}$, dentro do nível de $0,5 \mathrm{ppm}$ de manganês $\left(\mathrm{Mn}_{1}\right)$, o cultivar Santa Cruz Kada absorveu 75,7\% de sua exigência em fósforo ao passo que o cultivar Ronita $\mathrm{N}$ absorveu apenas $63,4 \%$.

Além disso, os dados da Tabela 7, indicam que o cultivar Ronita $\mathrm{N}$ é mais exigente que o cultivar Santa Cruz Kada, com relação ao fósforo.

FOY et alii (1973), constataram que entre cultivares de tomateiro, os mais tolerantes à acidez do solo são no geral os menos exigentes em nutrientes, inclusive fósforo.

\section{Cálcio}

Os dados de concentração de cálcio nas folhas inferiores e nas raízes das plantas são apresentadas na Tabela 8, os dados de quantidade total 
absorvida, na Tabela 9 e os de concentração do elemento nas diversas partes da planta, na Tabela 10.

A análise estatística permite as seguintes observações sobre os dacios da Tabela 8.

Tabela 8 - Teor $(\%)$ de cálcio nas folhas inferiores e nas raízes. Média de 4 repetições.

\begin{tabular}{|c|c|c|c|c|c|}
\hline \multicolumn{2}{|c|}{ Níveis } & \multicolumn{2}{|c|}{$\mathrm{Ca}$ nas folhas inferiores } & \multicolumn{2}{|c|}{$\mathrm{Ca}$ nas raizes } \\
\hline $\mathrm{Mn}(\mathrm{ppm})$ & $\mathrm{Al}$ (ppm) & Ronita N & Sta. Cruz Kada & Ronita N & Sta. Cruz Kada \\
\hline \multirow{4}{*}{0,5} & 0,0 & 3.77 & 2,86 & 0,67 & 0,61 \\
\hline & 10,0 & 3,24 & 2,78 & 0,47 & 0,57 \\
\hline & 20,0 & 3,10 & 2,90 & 0,48 & 0,53 \\
\hline & 0,0 & 4,05 & 3,08 & 0,63 & 0,61 \\
\hline \multirow[t]{2}{*}{1,5} & 10,0 & 3,97 & 3,08 & 0,59 & 0,57 \\
\hline & 20,0 & 3,70 & 3,17 & 0,57 & 0,63 \\
\hline & 0,0 & 3,68 & 2,77 & 0,64 & 0,61 \\
\hline \multirow[t]{2}{*}{3,0} & 10,0 & 3,64 & 2,77 & 0,59 & 0,68 \\
\hline & 20,0 & 3,52 & 3,40 & 0,52 & 0,55 \\
\hline \multirow{2}{*}{\multicolumn{2}{|c|}{$\begin{array}{l}\text { d.m.s. (Tukey 5\%) } \\
\text { C.V. }\end{array}$}} & 0,30 & 0,29 & 0,09 & 0,09 \\
\hline & & $4,65 \%$ & $5,50 \%$ & $9,46 \%$ & $8,96 \%$ \\
\hline
\end{tabular}

Efeito das doses de alumínio

Cultivar Ronita $\mathrm{N}$ - Os acréscimos nas doses de alumínio provocou diminuição no teor de cálcio, nas folhas e nas raízes das plantas dentro do nível de 0,5 ppm de manganês na solução nutritiva. Dentro do nível $1,5 \mathrm{ppm}$ de manganês o efeito foi observado apenas nas folhas e para o nível 3,0 ppm do micronutriente ocorreu o inverso do anteriur, isto é, o efeito foi verificado apenas nas raízes.

Cultivar Santa Cruz Kada - Os acréscimos nas doses de alumínio não alteraram a concentração de cálcio nas folhas e nas raízes dius plantas dentro dos níveis de 0,5 e 1,5 ppm de manganês na solução nutritiva. Mas, a maior dose de alumínio, dentro do nível de 3,0 pprn ảe manganês provocou acréscimo no teor de cálcio nas folhas e diminuição de concentração nas raízes.

Efeito das doses de manganês

Cultivar Ronita N - Nos níveis de 10,0 e 20,0 ppm de alumínio ¿om o incremento nas doses de manganês houve tendência a aumentar a concentração de cálcio nas folhas e nas raízes das plantas. 
Cultivar Santa Cruz Kada - Dentro do nível de 10,0 ppm de alumínio, o primeiro incremento na dose de manganês provocou aumento no teor de cálcio e o segundo incremento, uma diminuição no teor do nutriente, nas folhas. Nas raízes o efeito geral do aumento das doses de manganês não foi significativo $(F=1,69)$.

Os dados de quantidade total absorvida de cálcio (Tabela 9) evidenciam que no geral, o efeito das doses de alumínio foi o de provorar diminuição na absorção de cálcio. Desta forma os aumentos verificados de concentração de cálcio em alguns casos, associados ao aumento de alumínio na solução, parece ser devido a um efeito depressivo do alumínio no crescimento das plantas (efeito de concentração).

Com relação ao efeito de doses de manganês no aumento de absorção de cálcio (dados de quantidade total absorvida) este foi verificado apenas para o cultivar Ronita $\mathrm{N}$, e pode estar relacionado com o cfe to benéfico do nível 1,5 ppm de $\mathrm{Mn}$ no crescimento deste cultivar. Errbera a literatura apresente controvérsias, o aumento no teor de cálcio nos tecidos de plantas, provocado pelo aumento de doses de manganês fornecidas tem sido verificado (MORRIS \& PIERRE, 1949; REES \& SIDRAK, 1961).

Tabela 9 - Quantidade ( $\mathrm{mg}$ ) total de $\mathrm{Ca}$ absorvida, por duas plantas. Média de 4 repetições.

\begin{tabular}{|c|c|c|c|}
\hline \multicolumn{2}{|c|}{ Níveis } & \multicolumn{2}{|c|}{ Quantidade de cálcio absorvida } \\
\hline $\operatorname{Mn}(\mathrm{ppm})$ & $\mathrm{Al}(\mathrm{ppm})$ & Ronita N & Santa Cruz Kada \\
\hline \multirow{3}{*}{0,5} & 0,0 & 226 & 178 \\
\hline & 10,0 & 170 & 170 \\
\hline & 20.0 & 143 & 165 \\
\hline \multirow{3}{*}{1,5} & 0,0 & 272 & 164 \\
\hline & 10,0 & 219 & 167 \\
\hline & 20,0 & 165 & 177 \\
\hline \multirow{3}{*}{3,0} & 0,0 & 210 & 161 \\
\hline & 10,0 & 175 & 164 \\
\hline & 20,0 & 132 & 152 \\
\hline \multirow{2}{*}{\multicolumn{2}{|c|}{$\begin{array}{l}\text { d.m.s. (Tukey 5\%) } \\
\text { C.V. }\end{array}$}} & 17 & 25 \\
\hline & & $5,25 \%$ & $8,46 \%$ \\
\hline
\end{tabular}


E comumente aceito que o alumínio deprime a absorção de cálcio pelas plantas. LEE (1971) admite que o alumínio compete co mo cáicio pelos sítios ativos de absorção das raízes. Entretanto alguns autores evidenciam que é, às vezes, impossível correlacionar aumento de níveis de alumínio em solução nutritiva com diminuição do teor de cálcio nas diversas partes das plantas (CRUZ et alii, 1067a e FOY et alii, 1973).

Mais controvertido que o efeito do alumínio na absorção de cálcio, é o efeito daquele elemento na translocação do nutriente, das raízes às partes aéreas (FOY, 1974).

CLARKSON (1970), citado por FOY (1974) verificou que o alurainio tende a reduzir a ligação do cálcio com as cargas negativas que ocorrem nos espaços livres aparentes das raízes das plantas, bloqueancio, neutralizando ou revertendo essas cargas. Este efeito, que como já se verificou, auxilia a absorção de anions pelas plantas, provavelmente poderá mascarar possíveis efeitos depressivos dos íons alumínio na translocação do cálcio. MUNNS (1965), apesar disto, verificou diminuição na translocação do cálcio das raízes às partes aéreas de leguminosas resultante da ação do alumínio.

No presente experimento, confrontando os dados de concentração de cálcio nas raízes e nas folhas pode-se admitir que o alumínio deprimiu a absorção de cálcio, mas não há indicações que houvesse afetado a translocação, das raízes às partes aéreas.

Os dados da Tabela 10, demonstram ainda que o cultivar Ronita $\mathbf{N}$ é mais exigente que o cultivar Santa Cruz Kada, em cálcio Este aspecto tem sido mencionado na literatura, como indicativo de maior sensibilidade à acidez do solo (CHAPMAN, 1966) e a níveis de alumínio em solução nutritiva (FOY et alii, 1973).

Tabela 10 - Concentração de cálcio nas diversas partes da planta. Média de 4 repetições.

\begin{tabular}{lcccc}
\hline \multirow{2}{*}{ Cultivares } & \multicolumn{3}{c}{ Concentração (\%) de cálcio na matéria seca } \\
\cline { 2 - 4 } & $\begin{array}{c}\text { folhas } \\
\text { superiores }\end{array}$ & $\begin{array}{c}\text { folhas } \\
\text { inferiores }\end{array}$ & hastes & raízes \\
\hline \hline Ronita $\mathrm{N}$ & 1,46 & 3,77 & 1,36 & 0,67 \\
Santa Cruz Kada & 1,12 & 2,86 & 0,82 & 0,61 \\
\hline F (entre cultivares) & $=1.180,17 * *$ & & \\
C.V. $=3,78 \%$ & & & & \\
\hline
\end{tabular}

Significativo a $1 \%$. 
Ferro

Os dados sobre a concentração de ferro nas folhas inferiores e rias raízes das plantas, são apresentados nas Tabelas 11 e 12 .

Tabela 11 - Teor $(\mathrm{ppm})$ de ferro nas folhas inferiores e nas raízes. Média de 4 repetições,

\begin{tabular}{|c|c|c|c|c|c|}
\hline \multicolumn{2}{|c|}{ Níveis } & \multicolumn{2}{|c|}{$\mathrm{Fe}$ nas folhas inferiores } & \multicolumn{2}{|c|}{$\mathrm{Fe}$ nas raízes } \\
\hline $\operatorname{Mn}(\mathrm{ppm})$ & $\mathrm{Al}(\mathrm{ppm})$ & Ronita N & Sta. Cruz Kada & Ronita N & Sta. Cruz Kada \\
\hline \multirow{3}{*}{0,5} & 0,0 & 401 & 354 & 698 & 849 \\
\hline & 10,0 & 497 & 393 & 869 & 793 \\
\hline & 20,0 & 658 & 486 & 641 & 794 \\
\hline \multirow{3}{*}{1,5} & 0,0 & 475 & 655 & 780 & 909 \\
\hline & 10,0 & 616 & 357 & 712 & 903 \\
\hline & 20,0 & 422 & 476 & 822 & 846 \\
\hline \multirow{3}{*}{3,0} & 0,0 & 561 & 388 & 696 & 975 \\
\hline & 10,0 & 745 & 475 & 720 & 832 \\
\hline & 20,0 & 881 & 542 & 711 & 669 \\
\hline \multirow{2}{*}{\multicolumn{2}{|c|}{$\begin{array}{l}\text { d.m.s. (Tukey 5\%) } \\
\text { C.V. }\end{array}$}} & 152 & 123 & 184 & 298 \\
\hline & & $14,8 \%$ & $15,3 \%$ & $14,2 \%$ & $14,1 \%$ \\
\hline
\end{tabular}

Tabela 12 - Quantidade (ug) total de Fe absorvida por duas plantas. Média de 4 repetições.

\begin{tabular}{|c|c|c|c|}
\hline \multicolumn{2}{|c|}{ Níveis } & \multicolumn{2}{|c|}{ Quantidade de ferro absorvida } \\
\hline Mn (ppm) & $\mathrm{Al}(\mathrm{ppm})$ & Ronita $\mathrm{N}$ & Santa Cruz Kada \\
\hline \multirow{3}{*}{0,5} & 0,0 & 4.545 & 3.817 \\
\hline & 10,0 & 4.316 & 3.749 \\
\hline & 20,0 & 3.923 & 3.803 \\
\hline \multirow{3}{*}{1,5} & 0,0 & 6.017 & 4.243 \\
\hline & 10,0 & & \\
\hline & 20,0 & 3.752 & 4.187 \\
\hline \multirow{3}{*}{3,0} & 0,0 & 5.257 & 4.241 \\
\hline & 10,0 & 5.154 & 4.216 \\
\hline & 20,0 & 4.445 & 3.494 \\
\hline \multirow{2}{*}{\multicolumn{2}{|c|}{$\begin{array}{l}\text { d.m.s. (Tukey 5\%) } \\
\text { C.V. }\end{array}$}} & 795 & 836 \\
\hline & & $9,5 \%$ & $12,2 \%$ \\
\hline
\end{tabular}


A análise estatística mostrou efeitos significativos dos tratamentos com alumínio e manganês sobre a concentração de ferro na parte aécea e nas raízes das plantas do cultivar Ronita $\mathrm{N}$ bem como sobre a quanti dade total absorvida do elemento. Para o cultivar Santa Cruz Kada os efeitos também foram significativos para concentração de ferro na parte aérea mas, nas raízes apenas o efeito de doses de alumínio foi significativo, não havendo significância para os efeitos do manganês e também para a interação $\mathrm{Al} \times \mathrm{Mn}$. Em relação à quantidade total absorvida do elemento, o efeito não foi significativo igualmente.

A tendência mais geral foi de que tanto o aumento nos níveis de alumínio quanto de manganês em solução nutritiva promovesse um aumento na concentração de ferro nas folhas e também nas raízes das plantas de ambos os cultivares. Todavia, em algumas combinações de tratamentos ocorreu o inverso. Por exemplo, o aumento de doses de alumínio promoveu decréscimo no teor de ferro nas folhas do cultivar Santa Cruz Kada, dentro do nível de $\mathbf{M n}$ de $1,5 \mathrm{ppm}$. Também quando se aumentou o nível de Mn de 1,5 para 3,0 ppm nos tratamentos com nível zero de alumínio ocorreu ainda decréscimo no teor de ferro nas folhas do cultivar Santa Cruz Kada.

Por outro lado, quando se examina os dados de quantidade total absorvida de ferro pelas plantas verifica-se um efeito no geral diverso daqueles dados de concentração, em relação aos níveis de alumãnio. Por esses dados, o aumento de alumínio provocou a diminuição na absorção de ferro.

Ora, se o aumento nas doses dealumínio em solução teve como reflexo um aumento na concentração de ferro nas folhas e por outro lado, uma diminuição na quantidade total absorvida do elemento, pode-se inferir que essas variações são devidas mais ao efeito do alumínio no crescimento das plantas, que as possíveis interações entre alumínio e ferro no fenômeno da absorção iônica radicular. Os dados de quantidade do elemento absorvido pelo cultivar Santa Cruz Kada em que as doses de alumínio não afetaram o desenvolvimento das plantas mostra um efeito não significativo de doses de alumínio reafirmando a hipótese anteriormente levantada.

Outro aspecto interessante verificado foi a tendência do aumento no nível de manganês de provocar aumento na absorção de ferro o que pode ser constatado tanto nos dados de concentração do elemento nas folhas quanto nos de quantidade total absorvida. Esses dados à primeira vista parecem contraditórios ao conceito de que a toxidez de Mn traduz-se em muitos casos numa indução de deficiência de ferro. A indução de deficiência de ferro pelo manganês parece ser devida à inativação de parte do ferro metabólico enquanto que, no presente caso, foi analisado o teor de ferro total. Por outro lado, o efeito do manganês de aumentar o teor de ferro total das plantas já tem sido verificado (RIEKELS \& LINGLE, 1966). 
Outros aspectos podem explicar também a razão do manganês não induzir deficiência de ferro, em alguns casos. Assim é que ZHIZNEVSKAYA (1973), afirma que a interferência do manganês na absorção de ferro ocorre a nível celular. Provavelmente ambos sejam absorvidos por um mecanismo comum que parece ter maior afinidade pelo ferro do que pelo manganês.

Muitos agentes quelantes aumentam a disponibilidade do ferro e outros íons (metais) evitando a precipitação no meio bem como na planta. Em muitos casos verifica-se que toda a molécula complexa parece ser deslocada para a parte aérea (BARTLETT \& RIEGO, 1972).

\section{Manganês}

Os dados de concentração de Mn na parte aérea e raízes das plantas e os dados de quantidade total absorvida do elemento, são apresentados nas Tabelas 13 e 14 .

Tabela 13 - Teor (ppm) de Mn nas folhas inferiores e nas raízes. Média de 4 repetições.

\begin{tabular}{|c|c|c|c|c|c|}
\hline \multicolumn{2}{|c|}{ Níveis } & \multicolumn{2}{|c|}{ Mn nas folhas inferiores } & \multicolumn{2}{|c|}{ Mn nas raízes } \\
\hline $\mathrm{Mn}(\mathrm{ppm})$ & $\mathrm{Al}(\mathrm{ppm})$ & Ronita $N$ & Sta. Cruz Kada & Ronita $\mathrm{N}$ & Sta. Cruz Kada \\
\hline \multirow{3}{*}{0,5} & 0,0 & 32 & 24 & 87 & 105 \\
\hline & 10,0 & 26 & 27 & 99 & 79 \\
\hline & 20,0 & 27 & 40 & 82 & 149 \\
\hline \multirow{3}{*}{1,5} & 0,0 & 64 & 57 & 89 & 199 \\
\hline & 10,0 & 64 & 40 & 96 & 114 \\
\hline & 20,0 & 63 & 42 & 120 & 206 \\
\hline \multirow{3}{*}{3,0} & 0,0 & 92 & 43 & 164 & 195 \\
\hline & 10,0 & 80 & 61 & 247 & 188 \\
\hline & 20,0 & 99 & 82 & 142 & 178 \\
\hline \multirow{2}{*}{\multicolumn{2}{|c|}{$\begin{array}{l}\text { d.m.s. (Tukey 5\%) } \\
\text { C.V. }\end{array}$}} & 20 & 15 & 32 & 42 \\
\hline & & $18,5 \%$ & $18,7 \%$ & $14,8 \%$ & $12,2 \%$ \\
\hline
\end{tabular}

A análise estatística mostrou que as doses de alumínio não influíram na concentração de manganês na parte aérea das plantas do cultivar Ronita N, mas teve efeito significativo na concentração do elemento nas raízes. Com relação ao cultivar Santa Cruz Kada, o efeito das 
Tabela 14 - Quantidade (ug) total de Mn absorvida por duas plantas. Média de 4 repetições.

\begin{tabular}{|c|c|c|c|}
\hline \multicolumn{2}{|c|}{ Níveis } & \multicolumn{2}{|c|}{ Quantidade de Mn absorvida } \\
\hline $\mathrm{Mn}(\mathrm{ppm})$ & $\mathrm{Al}(\mathrm{ppm})$ & Ronita N & Santa Cruz Kada \\
\hline \multirow{3}{*}{0,5} & 0,0 & 455 & 360 \\
\hline & 10,0 & 343 & 308 \\
\hline & 23,0 & 234 & 393 \\
\hline \multirow{3}{*}{1,5} & 0,0 & 731 & 530 \\
\hline & 10,0 & 661 & 384 \\
\hline & 20,0 & 541 & 534 \\
\hline \multirow{3}{*}{3,0} & 0,0 & 878 & 667 \\
\hline & 16,0 & 875 & 615 \\
\hline & 20,0 & 656 & 630 \\
\hline \multirow{2}{*}{\multicolumn{2}{|c|}{$\begin{array}{l}\text { d.m.s. (Tukey 5\%) } \\
\text { C.V. }\end{array}$}} & 94 & 98 \\
\hline & & $8,9 \%$ & $11,4 \%$ \\
\hline
\end{tabular}

doses de alumínio foi significativo nas concentrações de manganês tanto na parte aérea quanto nas raízes.

Em termos de concentração de nutrientes, o efeito do alumínio sobre a absorção de manganês não foi bem definido porque ora provocou aumento, ora diminuição, em função também das doses de manganês. Entretanto quando se considera os dados de quantidade absorvida do elemento, verifica-se que os aumentos nos níveis de alumínio provocaram diminuição na absorção de manganês, dentro de todos os níveis do nutriente para o cultivar Ronita $\mathrm{N}$ e em pelo menos um caso (nos tratamentos com 1,5 ppm de Mn) para o cultivar Santa Cruz Kada.

Desta forma, generalizando, pode-se afirmar que houve tendência de que o aumento nas doses de alumínio provocasse diminuição na absorção de manganês mas esse efeito não foi muito marcante e parece ter sido afetado, inclusive, pelo efeito do alumínio no crescimento das plantas.

Os aumentos nos níveis de manganês na solução, como se poderia esperar, provocou um aumento quase que linear na concentração do elemento nos tecidos das plantas dos dois cultivares e também em termos de quantidade total absorvida. Mas, como foi visto na literatura revisada, os níveis de manganês na parte aérea das plntas, de 20 a 200 ppm são tidos como normais e os níveis deaté $500 \mathrm{ppm}$ podem não ser excessivos. Como o maior nível de manganês fornecido em solução $(3,0 \mathrm{ppm})$ 
proporcionou uma concentração máxima do elemento nas plantas, de 99 ppm, conclui-se que, no sistema empregado, as plantas tiveram suprimento adequado de manganês, distante de ser excessivo.

O sistema de fornecimento de solução nutritiva, alternadamente com soluções de alumínio ou com água destilada parece não ser suficiente para explicar os teores de manganês, relativamente baixos, nos tecidos das plantas porque os demais nutrientes foram fornecidos da mesma forma e atingiram níveis bastante altos como por exemplo o fósforo e o cálcio. Desta forma, deduz-se que, essas plantas absorvem pouco manganês e que o suprimento de até $3,0 \mathrm{ppm}$ é insuficiente para induzir toxidez o que, em parte difere das informações da literatura (CANDELA \& HEWITT, 1957; KIRSCH et alii, 1960).

\section{Aluminio}

Os dados de teores de alumínio nas raízes e nas folhas das plantas são apresentados na Tabela 15.

Tabela 15 - Teor (ppm) de alumínio nas folhas inefriores e nas raízes. Mélia de 4 repetições.

\begin{tabular}{|c|c|c|c|c|c|}
\hline \multicolumn{2}{|c|}{ Níveis } & \multicolumn{2}{|c|}{ Al nas follas inferiores } & \multicolumn{2}{|c|}{ Mn nas raízes } \\
\hline $\operatorname{Mn}(\mathrm{ppm})$ & Al (ppm) & Ronita N & Sta. Cruz Kada & Ronita $\mathrm{N}$ & Sta. Cruz Kada \\
\hline \multirow[t]{2}{*}{0,5} & 10,0 & 39 & 30 & 108 & 58 \\
\hline & 20,0 & 61 & 44 & 187 & 145 \\
\hline \multirow[t]{2}{*}{1,5} & 10,0 & 77 & 38 & 62 & 68 \\
\hline & 20,0 & 105 & 46 & 111 & 109 \\
\hline \multirow[t]{2}{*}{3,0} & 10,0 & 89 & 32 & 97 & 59 \\
\hline & 20,0 & 118 & 59 & 140 & 85 \\
\hline
\end{tabular}

A análise de alumínio foi feita no extrato obtido pela incineração de 2,000 g de matéria seca vegetal.

Para isso, foi necessária a reunião das repetições 3 a 3 , ao acaso, das diversas partes da planta para obtenção da quantidade de matéria seca necessária à análise. Desta forma, a análíse estatística não foi efetuada para os dados de teores de alumínio nas folhas e nas raízes.

Embora sem apoio estatístico, os dados mostram que o cultivar Ronita $\mathrm{N}$ absorveu mais alumínio como já havia absorvido também 
maior quantidade dos nutrientes em estudo, que o cultivar Santa Cruz Kada.

Aparentemente, o aumento nas doses de manganês tenderam a aumentar os níveis de alumínio na parte aérea e ao mesmo tempo diminuir os níveis do elemento, nas raízes. Em outras palavras, com o aumento do nível de manganês em solução parece ter havido uma tendência de maior transferência do alumínio, das raízes às partes aéreas das plantas de ambos os cultivares.

Os teores de alumínio nas raízes das plantas foram superiores aos teores das folhas. Embora os teores obtidos de alumínio nas folhas sejam comparáveis ao obtido por outros autores (FOY et alii, 1973) os teores encontrados nas raízes foram muitas vezes inferiores aos citados pelos referidos autores. Diversas hipótese podem ser levantadas para explicar esta discrepância mas o método de fornecimento alternado de alumínio e fósforo e a lavagem intensa a que foram submetidas as raízes para seperá-las do quartzo moído aderente parecem ser importantes.

Como explicam aqueles autores, os níveis de alumínio na parte aérea do tomateiro, que encontraram (entre 41 e $127 \mathrm{ppm}$ ) não podem ser considerados altos e é duvidoso que esses níveis, por si só, sejam causas de depressão no crescimento das plantas.

A coerência entre os dois experimentos mostra que no solo utilizado, com níveis altos de manganês e alumínio, a causa predominante do mau desenvolvimento das plantas foi o nível alto de alumínio. Confirma-se assim as considerações de JUSTE (1970) de que, quando associados, o alumínio deprimindo a absorção de manganês prevalece como elemento tóxico.

\section{Considerações Gerais}

Uma análise conjunta dos resultados do segundo experimento e uma relação entre os dois experimento parece necessária não só para possibilitar as conclusões, reunindo a série de informações obtidas, bem como para atender alguns aspectos que limitam conclusões mais amplas sobre o problema estudado.

Inicialmente, houve coerência entre os dois experimentos, no sentido de que tanto o cultivar mais sensível à acidez do solo quanto o mais tolerante apresentaram essas mesmas características com relação aos níveis de alumínio em solução nutritiva. Aconteceram, todavia, algumas discrepâncias. O desenvolvimento do cultivar Santa Cruz Kada, por exemplo, nas condições "padrões" de solo e solução nutritiva foi diferente em cada experimento. Isto talvez possa indicar que além das condições de acidez indicadas (níveis de alumínio e manganês) alguma carac- 
terística química ou física do solo terá afetado o desenvolvimento das plantas, atuando diferentemente entre os culivares.

As plantas do cultivar Ronita $\mathrm{N}$ apresentaram germinação mais rápida (4 dias de diferença) que as do culivar Santa Cruz Kada, em solução nutritiva onde a irrigação talvez tenha sido um pouco deficiente no início, em vista da drenagem estabelecida nos vasos. Essa diferença de germinação não foi verificada no solo onde o suprimento de água foi mantido próximo à capacidade de campo. Parece, portanto, ser uma qualidade inerente do cultivar Ronita $\mathrm{N}$ a capacidade de germinar mais rapidamente que o cultivar Santa Cruz Kada em condições de ligeira deficiência de água. Melhores informações a esse respeito deverão ser buscadas em novos experimentos. Outro aspecto, ligado ao problema, diz respeito ao desenvolvimento do sistema radicular. Proporcionalmente à parte aérea, nos tratamentos "padrões", verificou-se que o desenvolvimento radicular do cultivar Ronita $N$ é maior que o do Santa Cruz Kada. Ora, já se sabe (VOSE \& RANDALL, 1972) que a rapidez de implantação das culturas (germinação e o crescimento inicial), é um fator que tem mascarado resultados de experimentos sobre tolerância à acidez, conduzidos em solo.

Esses problemas devem ser devidamente considerados na inter-relação dos dois experimentos, bem como na tentativa natural de se estabelecer um paralelo entre os resultados de tolerância das plantas a níveis de alumínio e manganês em solução nutritiva com os resultados do cultivo dessas plantas em solo ácido.

Os dados do experimento conduzido em solução nutritiva mostraram que o cultivar Ronita $\mathrm{N}$ foi mais exigente em fósforo e cálcio além de absorver maiores quantidades de alumínio que as plantas do cultivar Santa Sruz Kada.

Com relação ao manganês as plantas tiveram comportamentos que podem ser considerados similares salientando-se que os níveis mais altos do elemento, fornecidos em solução nutritiva, não foram prejudiciais ao crescimento das plantas, como seria desejável. Todavia, houve interação alumínio-manganês afetando a avaliação do efeito dos tratamentos em quase todos os parâmetros considerados.

Com base nas respostas das plantas à correção do solo (calagem e nível mais alto de adubação) no primeiro experimento, verificou-se que o grau de tolerância ao alumínio, do cultivar Santa Cruz Kada, apesar de ser maior que o do Ronita $\mathrm{N}$, é contudo, relativamente baixo. É válido portanto, esperar-se, ainda, boas respostas dessas plantas à calagem, nos cultivos em solos ácidos. É bastante provável também que, para as mesmas condições de solo, o cultivar Ronita $\mathrm{N}$ exija maior quantidade de corretivo que o cultivar Santa CruzKada para atingir seu potencial de produção. 


\title{
CONCLUSÕES
}

- O cultivo dos cultivares Santa Cruz Kada e Ronita N, em solução nutritiva, com níveis crescentes de alumínio e manganês demonstra ser o cultivar Santa Cruz Kada mais tolerante ao alumínio que o cultivar Ronita N.

- A maior sensibilidade do cultivar Ronita $\mathrm{N}$ ao alumínio é associada em parte à maior exigência em fósforo e cálcio pelo cultivar.

- O efeito depressivo do alumínio na absorção de fósforo e cálcio é mais pronunciado no cultivar Ronita $\mathrm{N}$ em relação ao cultivar Santa Cruz Kada.

- O cultivar Santa Cruz Kada apresenta maior capacidade de utilização do fósforo em presença de alumínio que o cultivar Ronita $\mathbf{N}$.

- O nível de 3,0 ppm de manganês na solução nutritiva é insuficiente para induzir toxidez aos cultivares.

- A tolerância do cultivar Santa Cruz Kada ao alumínio, embora maior que a do cultivar Ronita $\mathrm{N}$, apresenta-se em grau considerado baixo.

SUMMARY

\author{
TOLERANCE TO ALUMINUM AND MANGANESE OF TOMATO \\ (LYCOPERSICON ESCULENTUM MILL) CULTIVARS
}

Two experiments were conducted, under green house conditions, to investigate the tolerance of tomato cultivars to aluminum and manganase.

In the first experiment, six tomato cultivars: "Santa Cruz Kada" - "Angela IAC 3946" - "Vital" - "Roma VF" - "Pavebo 220" and "Ronita N", were cultivated in acid soil named "Latossol Roxo" wich contains high levels of aluminum and manganase.

In the second experiment, the cultivars Santa Cruz Kada and Ronita N which showed differences in tolerance to the acid soil were cultivated in a modified HOAGLAND \& ARNON nutrient solution with manganese levels of 0,$0 ; 10,0$ and $20,0 \mathrm{ppm}$ and aluminum levels of 0,$0 ; 10,0$ and $20,0 \mathrm{ppm}$.

The results obtained allowed to indicate cv. Santa Cruz Kada as more tolerante to aluminum than $\mathrm{cv}$. Ronita $\mathrm{N}$. The sensibility of this cultivar to aluminum is associated with a higher requirement in calcium and phosphorus, with a higher absorption of aluminum and with the effects of aluminum on the absorption of those nutrients. 
The tolerance of Santa Cruz Kada to aluminum, evem being higher than Ronita N, it can be considered of low degree, indicating that good responses to liming in acid soil can be obtained with these cultivars.

For the two cultivars studied in nutrient solution, no detrimental effects of manganese levels were observed.

\section{LITERATURA CITADA}

BARTLETT, R.J. \& D.S. RIEGO. 1972 - Effect of chelation on the toxity of aluminum. Plant and Soil, $37: 419-423$.

BINGHAM, F.T. 1966 - Phosphorus. In: CHAPMAN, H.D. Diagnostic criteria for plants and soils. California University, Division of Agricultural Sciences. p. 324-361.

CAMARGO, L.S., H.E. CAMPOS \& E. ABRAMIDES. - Infiucncia da calagem em solo ácido da formação glacial na produção do tomateiro. Bragantia, 24 :51-54. 1965.

CANDELA, M.I. \& J.E. HEWITT - Molybdenum as a plant nutrient. IX. The effects of different molybdenum and manganese supplies on yield and on the uptake and distribution of molybdenum in tomato plants grown in sand culture. J. Hort. Sci., 32: 149-161. 1957.

CHAPMAN, H.D. Calcium. In: CHAPMAN, H.D. - Diagnostic criteria for plants and soils. California, University. Division of Agricultural Sciences, p. 65-92. 1966.

CHURATA-MASCA, M.G.C. - Produção de tomate para industrialização através do sistema rasteiro. Jaboticabal, FMVAJ. 1974. 49 p. (Curso de extensão).

CHURATA-MASCA, M.G.C. 1975 - Recomendações práticas para a produção do tomate para fins industriais. Jaboticabal, F.M.V.A.J. 39 p. (Curso ministrado).

CLARKSON, D.T. - Metabolic aspects of aluminum toxicity and some posible mechanism for resistence. RORISON, I. Ecological aspects of Mineral Nutrition of Plants. Oxford, Blackwell. 1967.

CRUZ, A.D., H.P. HAAG, J.R. SARRUGE \& E. MALAVOLTA. 1967 - Interação entre alumínio e fósforo em duas variedades de trigo (Triticum vulgare L.) cultivado em solução nutritiva. Anais da ESALQ, 24:119-129.

CRUZ, A.D., H.P. HAAG, J.R. SARRUGE \& E. MALAVOLTA. 1967a. - Efeitos do alumínio no trigo (Triticum vulgare $\mathrm{L}$. var. Piratini) cultivado em solução nutritiva. Anais da ESALQ, $24: 107-117$.

FILGUEIRA, F.A.R. - Manual de Olericultura: cultura e comercialização de hortaliças. São Paulo, Ceres. 451 p. 1972.

FOY, C.D., G.C. GERLOFF \& W.H. GABELMEN - Differential effects of aluminum on the vegetative growth of tomato cultivars in acid soil and nutriente solution. J. Am. Soc. Hort. Sci., $98: 427-432.1973$.

FOY, C.D. - Aluminum toxicity in soils. In: CARSON, G.M. Plant Root and its Enviromment. Virginia, University, Sta. Charlottesville. 1974. p. 60-642. 
JACKSON, M.L. - Analisis quimico de suelos. In: Omega, S.A. Bercelona. 1964. 662 p.

JUSTE, C. - Actions toxiques des oligo-élements. Ann. Agron., 21:549-571. 1970.

KAYAMA, M. - Efeito de diversos tipos de calcário e sua compatibilidade com borax e gesso na produção do tomateiro. Minas Gerais, Universidade Rural. 1968. 59 p. (Tese para obtenção do grau de Mestre).

KIRSCH, R.K., M.E. HARWARD \& R.S. PETERSEN - Interrelasionships among iron, manganese and molybdenum in the growth and nutrition of tomatoes grown in culture solution. Plant and Soil, 12 :259-275. 1960.

LABANAUSKAS, C.K. - Manganese. In: CHAPMAN, H.D. Diagnostic criteria for plants and soils. California, University, Division of Agricultural Sciences. 1966. p. 264-285.

ALROCHE, F.A. - Efeitos da calagem sobre o complexo de troca de um latossolo tropical e os teores de cations absorvidos pelo tomate. Local de publicação, IICA da OEA. 1967. 80 p. (Tese para obtenção do título de Mestre).

LEE, C.R. - Influence of aluminum on plant growth and mineral nutrition of potatoes. Agron. J., 63 :604-608. 1971.

LINDSAY, W.L. \& W.A. NORWELL. 1969 - Development of a DTPA micronutrient soil test. Agron. Abst., 18:84. 1969.

MERCADO, B.T. \& VELASCO, J.R. 1961 - Effect of aluminum on the growth of coconut and other plants. Phillipp. Agr., 45 :268-274.

McLEAN, F.T. \& B.E. GILBERT - Aluminum toxicity. Plant Phksiol., 3 :293-303. 1928.

MORRIS, H.D. \& W.H. PIERRE - Minimum concentrations of manganese necessary for injury to various legumes in culture solutions. Agron. J., 41:107-112. 1949.

MUNNS, D.N. - Soil acidity and growth of a legume. II. Reactions of aluminum and phosphate in solution and effects of aluminum, phosphate, calcium and $\mathrm{pH}$ on Medicago sativa L. and Trifolium subterrameum L., in solution culture. Australian J. Agric. Res., $16: 743-755$. 1965 .

REES, W.J. \& G.D. SIDRAK - Interrelationships of aluminum and manganese toxicities toward plants. Plant and Soil, 14:101-117. 1961.

RIEKELS, J.W. \& J.C. LINGLE. 1966 - Iron uptake and translocation by tomato plants as influenced by root temperature and manganese nutrition. Plant Physiol., 41:1095-1101.

SARRUGE, J.R. \& H.P. HAAG. 1974 - Análises químicas em plantas. Piracicaba, Livroceres. $47 \mathrm{p}$.

SILVA, A.R. - Melhoramento genético para resistência à toxidez de alumínio e manganês no Brasil: antecedentes, necessidade e possibilidades. Tópicos para discussão e pesquisa. Ciência e Cultura, 28:147-149. 1976.

VOSE, P.B. \& P.J. RANDALL. 1972 - Resistence to aluminum and manganese toxicities in plants related to variety and cation exchange capacity. Nature, 196:85-86.

ZHIZNEVSKAYA, G.Y. 1973 - Iron in plant nutrition. Agrochimica, 17 :46-68. 
